\title{
A Comparative Study of the Performance of Wavelet Decomposition of Images using Kekre's Transform vis-a-vis Haar and Daubechies
}

\author{
Bijith Marakarkandy \\ TCET, Kandivali (E) \\ Mumbai 400101
}

\author{
Dr. B K Mishra \\ TCET ,Kandivali (E) \\ Mumbai 400101
}

\begin{abstract}
In recent years Image and Signal compression have been receiving a lot of attention by scientists and researchers in order to improve storage and transmission capabilities. In this study we have compared the performance of Kekre's wavelet with other wavelets viz. Haar and Daubechies 2 with respect to energy in the Low-Low (LL ), Low-High (LH) ,High-Low (HL) and High-High $(\mathrm{HH})$ bands. The energy distribution in each band is an indicator of the performance of the transform for image compression. It is found that the percentage of energy in the low-low band is equal for Kekre's and Haar wavelet. The daubechies 2 wavelet although offers a slightly higher energy compaction but the tradeoff is that the order of the filter being higher and therefore computational burden increases.
\end{abstract}

\section{General Terms}

Experimentation, Documentation, Performance, Design.

\section{Keywords}

Haar Wavelet, Kekre's Wavelet, Daubechies Wavelet.

\section{INTRODUCTION}

Wavelets are mathematical functions that cut up data into different frequency components, and then study each component with a resolution matched to its scale. They have advantages over traditional Fourier methods in analyzing physical situations where the signal contains discontinuities and sharp spikes. Wavelets were developed independently in the fields of mathematics, quantum physics, electrical engineering, and seismic geology. Interchanges between these fields during the last ten years have led to many new wavelet applications such as image compression, turbulence, human vision, radar, and earthquake prediction [1].

The basic concept in wavelet is to use a mother wavelet and then perform analysis using shifted and dilated versions of this mother wavelet [2]

Wavelet Transforms use different window functions to analyse different frequency bands of the signal $x(t)$. Different window functions $\psi(\mathrm{s}, \mathrm{b}, \mathrm{t})$; which are also called daughter wavelets they can be generated by dilation or compression of a mother wavelet $\psi(\mathrm{t})$, at different time frame. A scale is the inverse of its corresponding frequency. A continuous type of wavelet transform (CWT) that is applied to the signal $\mathrm{x}(\mathrm{t})$ can be defined as,

$\mathrm{w}(\mathrm{a}, \mathrm{b})=\frac{1}{\sqrt{a}} \int_{-\infty}^{\infty} x(t) \Psi(t-b) / a d t$
Where

a is the dilation factor, $\mathrm{b}$ is the translation factor and $\psi(\mathrm{t})$ is the mother wavelet.

$1 / \sqrt{ } a$ is an energy normalization term that makes wavelets of different scale have the same amount of energy.

\section{METHODOLOGY}

We have used three test images viz . lena ,rice and one band of a multispectral image of SanFrancisco bay area for comparison of the performance of Kekres transform with Haar and Daubechies wavelets.

THE KEKRE'S MATRIX [3 ]

Kekre's matrix can be generated using the expression

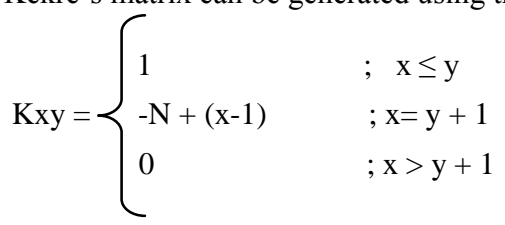

A 2x2 Kekres matrix obtained from the above expression is

$$
K(2)=\left[\begin{array}{cc}
1 & 1 \\
-1 & 1
\end{array}\right]
$$

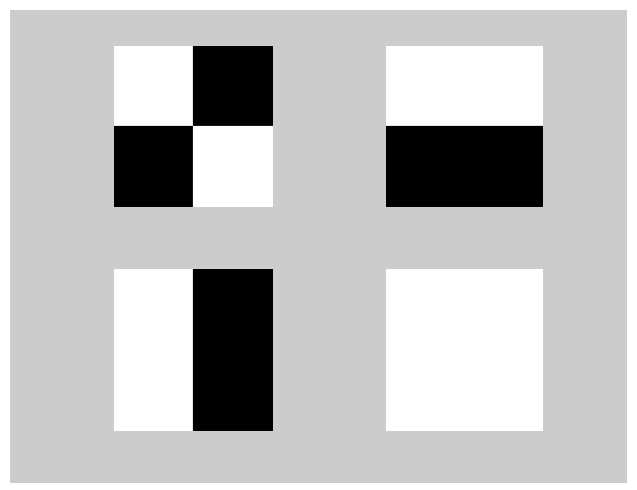

Figure 1. Two dimensional Kekres basis functions $(\mathrm{N}=2)$ 
A $3 \times 3$ Kekres matrix obtained from the above expression is

$$
\left[\begin{array}{ccc}
1 & 1 & 1 \\
-2 & 1 & 1 \\
0 & -1 & 1
\end{array}\right]
$$

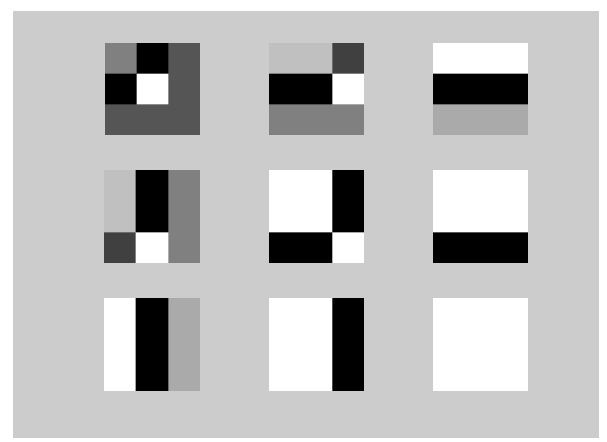

Figure 2 Two dimensional Kekre's basis functions $(\mathbf{N}=3)$

\section{PROPERTIES OF KEKRE'S WAVELET TRANSFORM \\ 3.1 Orthogonal}

The transform matrix $\mathrm{K}$ is said to be orthogonal if the following condition is satisfied.

$$
[\mathrm{K}][\mathrm{K}]^{\mathrm{T}}=[\mathrm{D}]
$$

Where $\mathrm{D}$ is the diagonal matrix.

Kekre's Wavelet Transform matrix satisfies this property and hence it is orthogonal.

The diagonal matrix value of Kekre's transform matrix of size $\mathrm{NxN}$ can be computed as

$$
D(x, y)= \begin{cases}2 & ; \text { if } x=y=N \\ N & ; \text { if } x=y=1 \\ 0 & ; \text { if } x \neq y \\ D(x+1, y+1)+2(N-x+1) & \text {; if } x=y=p \text { and } p \neq 1 \text { or } N\end{cases}
$$

\section{Asymmetric}

As the Kekre's transform is upper triangular matrix, it is asymmetric.

\subsection{Non-Involutional}

An involutionary function is a function that is its own inverse. So involutional transform is a transform which is inverse transform of itself. Kekre's transform is non involutional transform.

\subsection{Transform on Vector}

The Kekre's Wavelet transform on a column vector $\mathrm{f}$ is given by

$$
F=[K W] f
$$

And inverse is given by

$$
\mathrm{f}=[\mathrm{KW}]^{\mathrm{T}}[\mathrm{D}]^{-1} \mathrm{~F}
$$

\subsection{Transform on 2D Matrix}

Kekre's Wavelet transform on 2D matrix $\mathrm{f}$ is given by

$[\mathrm{F}]=[\mathrm{KW}][\mathrm{f}][\mathrm{KW}]^{\mathrm{T}}$

Obtaining Inverse: Calculate Diagonal matrix D as,

$$
[\mathrm{D}]=[\mathrm{KW}][\mathrm{KW}]^{\mathrm{T}}
$$

\begin{tabular}{|l|l|l|l|l|l|}
\hline D1 & 0 & 0 & 0 & 0 & 0 \\
\hline 0 & D2 & 0 & 0 & 0 & 0 \\
\hline 0 & 0 & D3 & 0 & 0 & 0 \\
\hline 0 & 0 & 0 & $\cdots$ & 0 & 0 \\
\hline 0 & 0 & 0 & 0 & $\cdots$ & 0 \\
\hline 0 & 0 & 0 & 0 & 0 & DN \\
\hline
\end{tabular}

Inverse is calculated as

$[\mathrm{f}]=[\mathrm{KW}]^{\mathrm{T}}[\mathrm{Fij} / \mathrm{Dij}][\mathrm{KW}]$

Where $\mathrm{Dij}=\mathrm{Di} * \mathrm{Dj} \quad ; 1 \leq \mathrm{i} \leq \mathrm{N}$ and $1 \leq \mathrm{j} \leq \mathrm{N}$

\section{DECOMPOSITION USING WAVELETS}

The basic idea of subband coding (SBC) is to split up the frequency band of the signal and then to code each subband using a coder and bit rate accurately matched to the statistics of that band [4].In Subband coding of images each row of the image is convolved with the coefficients of the LPF and HPF and downsampled by two, then we work on the image column wise and again downsample by two.If the original image is of size $\mathrm{NxN}$ after first level decomposition we obtain four images of size N/2 $\mathrm{x}$ $\mathrm{N} / 2$. It is usually found that out of the four sub images the LL subimage has most of the energy and other subimages have energy close to zero . Therefore the LL subimage may be decomposed further and the other subimages are usually not decomposed further.

\subsection{Kekre's wavelet [5]}

The first row of the Kekre's forward transform matrix is a Low Pass filter. The frequency response of the filter is shown in Fig. 3. This row is used as the impulse response of the low pass decomposition filter.

The impulse response of Kekres analysis filters are

$$
\begin{aligned}
& \mathrm{h} 0[\mathrm{n}]=[1,1] \mathrm{LPF} \\
& \mathrm{h} 1[\mathrm{n}]=[-1,1] \mathrm{HPF}
\end{aligned}
$$

$\left|\mathrm{H}_{0}\left(\mathrm{e}^{\mathrm{jw}}\right)\right|=\sqrt{2+2 \cos w}$

$\left|\mathrm{H}_{1}\left(\mathrm{e}^{\mathrm{jw}}\right)\right|=\sqrt{2-2 \operatorname{cosw}}$

$\left|\mathrm{H}_{0}(0)\right|=2,\left|\mathrm{H}_{0}(\pi / 2)\right|=\sqrt{2},\left|\mathrm{H}_{0}(\pi)\right|=0$ and $\left|\mathrm{H}_{1}(0)\right|=0$

$\left|\mathrm{H}_{1}(\pi / 2)\right|=\sqrt{2},\left|\mathrm{H}_{1}(\pi)\right|=2$ 

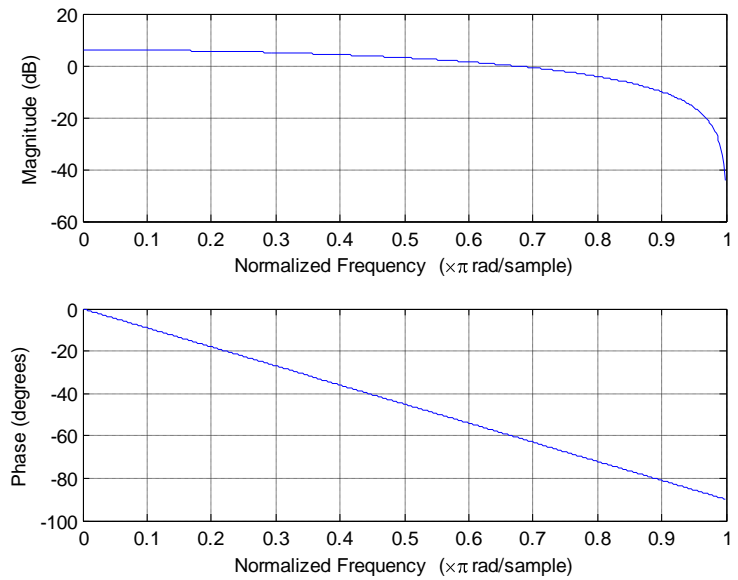

Figure 3. Frequency Response of Kekres Lowpass Decomposition Filter

The second row of the Kekres forward transform matrix is a High pass filter and its frequency response is as shown Fig.4 . This row is used as the impulse response of the high pass decomposition filter
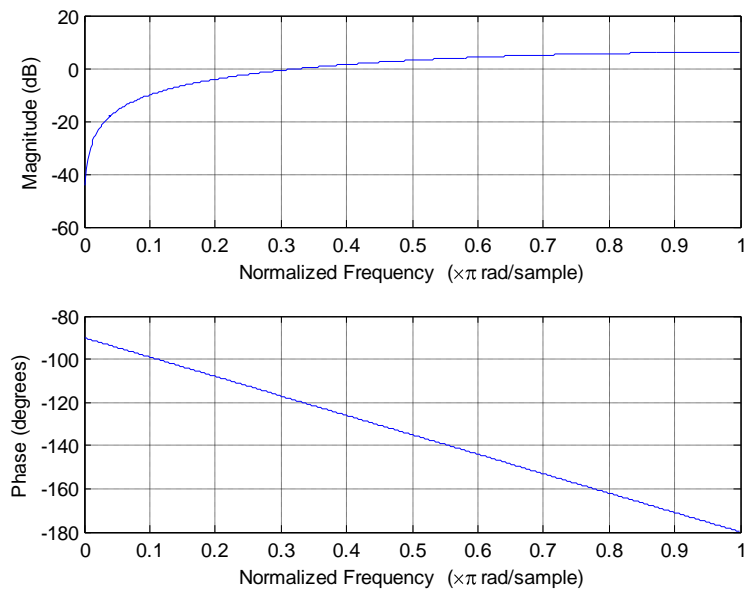

Figure 4. Frequency Response of Kekres Highpass decomposition filter
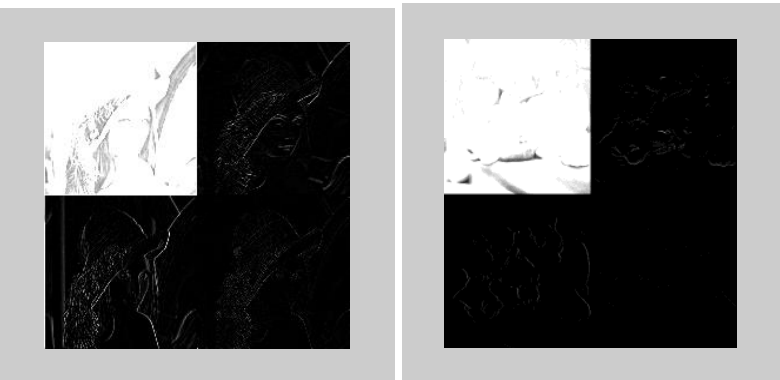

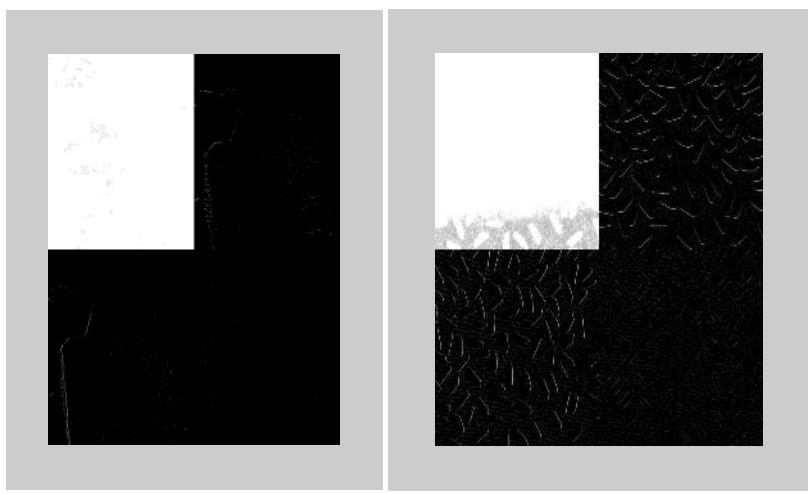

Figure 5 One level decomposition using Kekres wavelet transform

\subsection{Haar Wavelet}

The impulse response of Haar analysis filters are $\mathrm{h}_{0}[\mathrm{n}]=\left[\begin{array}{ll}0.7071 & 0.7071\end{array}\right] \mathrm{LPF}$

$\mathrm{h}_{1}[\mathrm{n}]=\left[\begin{array}{ll}-0.7071 & 0.7071\end{array}\right] \mathrm{HPF}$
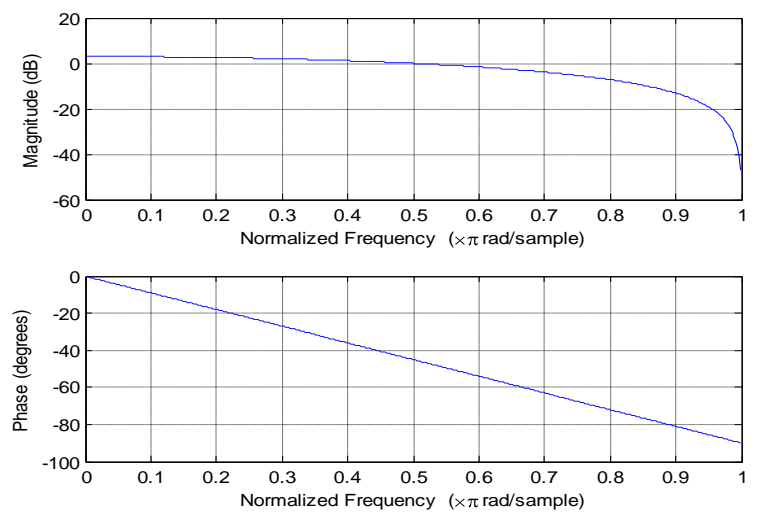

Figure 6 Frequency response of the LPF used in the Haar analysis filter bank.
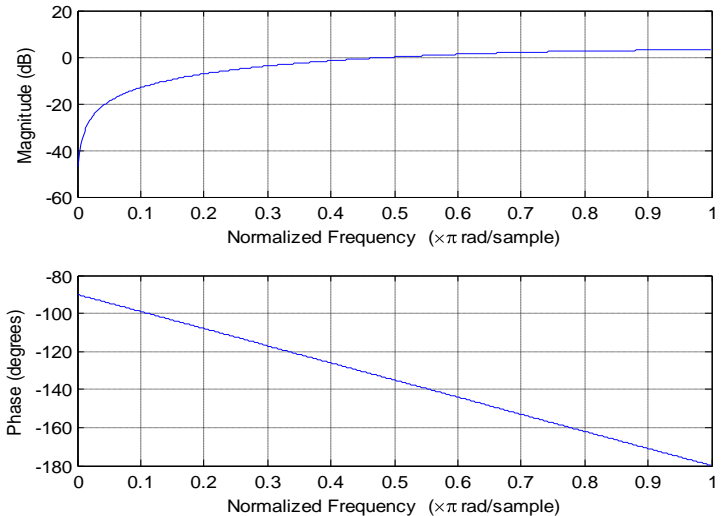

Figure 7 Frequency response of the HPF used in Haar analysis filter bank 

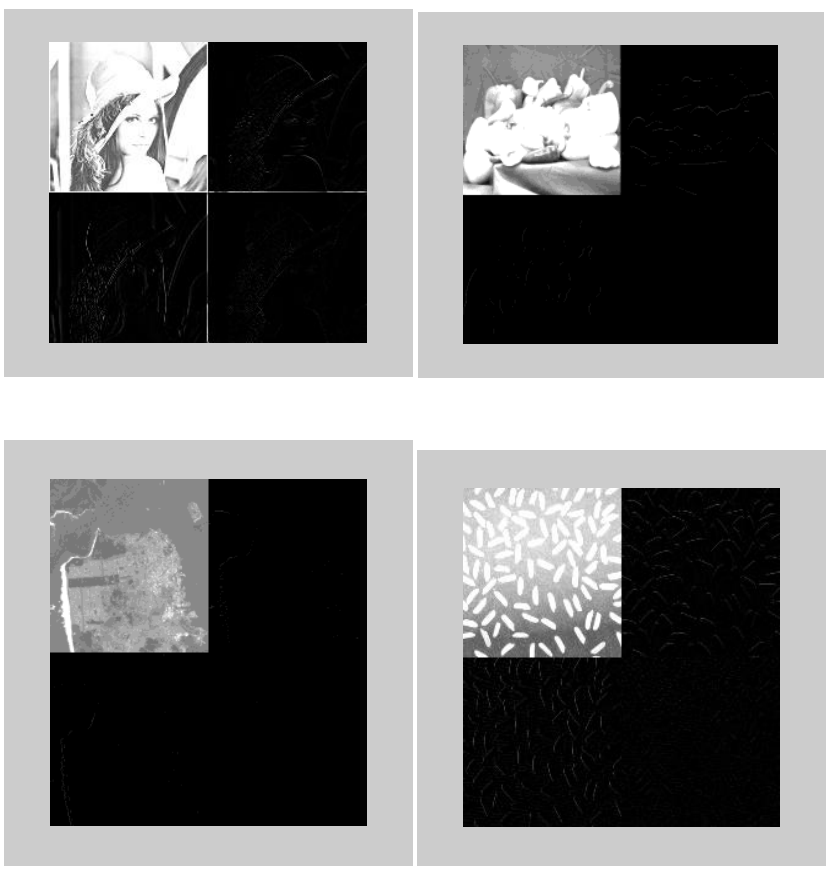

Figure 8 : One level decomposition using Haar wavelet transform.

\subsection{Daubechies Wavelet}

The impulse response of Daubechies 2 analysis filters are

$$
\begin{aligned}
& \mathrm{h}_{0}[\mathrm{n}]=\left[\begin{array}{lllll}
-0.1294 & 0.2241 & 0.8365 & 0.4830
\end{array}\right] \mathrm{LPF} \\
& \mathrm{h}_{1}[\mathrm{n}]=\left[\begin{array}{lllll}
-0.4830 & 0.8365 & -0.2241 & -0.1294
\end{array}\right] \mathrm{HPF}
\end{aligned}
$$
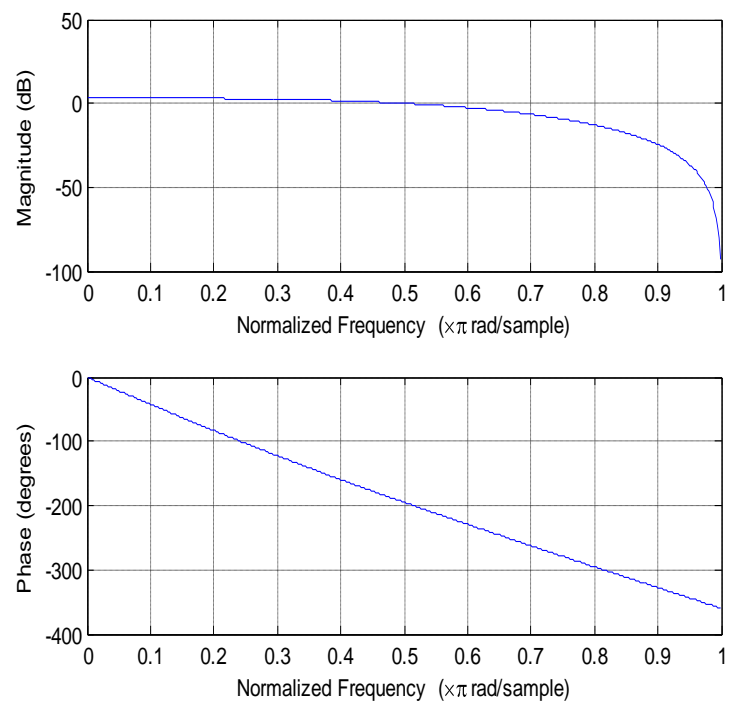

Figure 9 Frequency response of the LPF used in the Daubechies 2 analysis filter bank
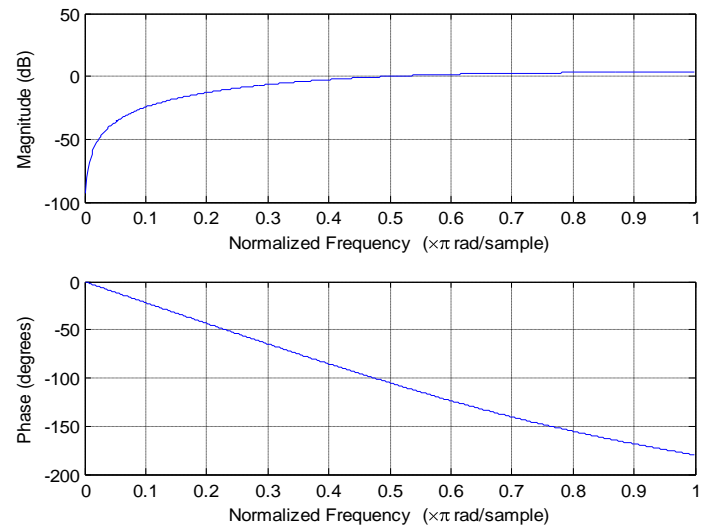

Figure 10 Frequency response of the HPF used in the Daubechies 2 analysis filter bank.
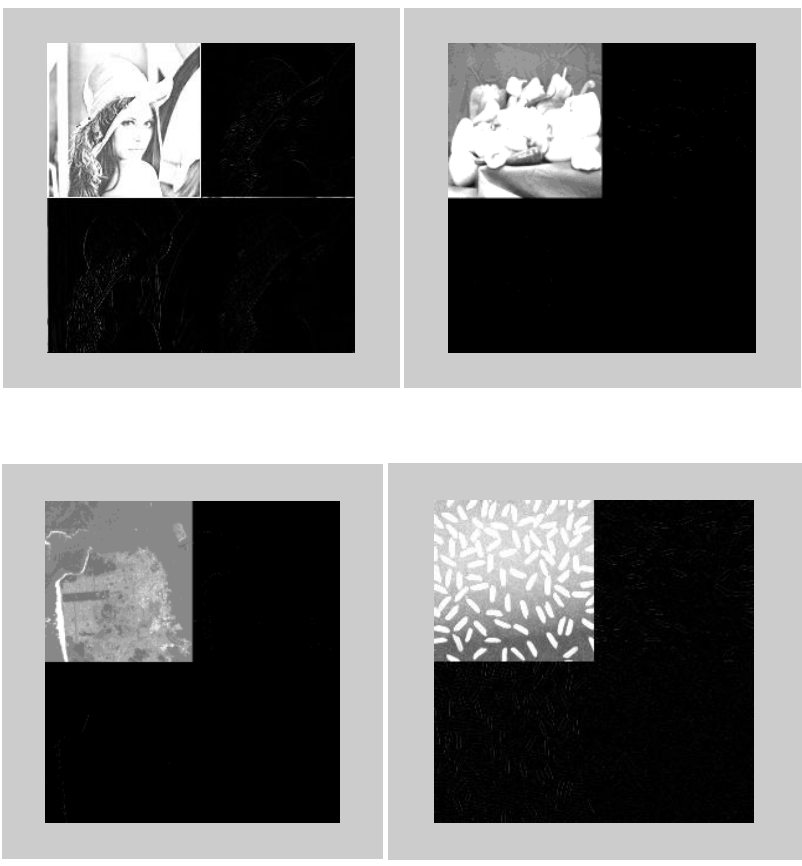

Figure 11:One level decomposition using Daubechies wavelet transform.

To perform image compression using the transform coding method is to take an image and apply a transform on the image to change its representation. The original image usually has its energy scattered throughout the image. The objective of taking the transform is to pack a lot of energy into as few pixels as possible. Energy compaction capability of the transform is a very useful property which allows allocation of more bits to high energy coefficients which occur in the LL band and fewer bits to low energy coefficients which are quantized and made zero.

When the image is decomposed using wavelets transform is taken most of the energy in the image relocates to the top LL band. Higher order filters are more efficient in decomposition than filters with lower order. However higher the order the number of computation i.e. multiply-add increases. 


\section{RESULTS AND DISCUSSION}

Table 1 Comparison of Wavelet Coefficients using Kekre, Haar and Db2 for Different Images.

\begin{tabular}{|c|c|c|c|c|c|}
\hline $\begin{array}{l}\text { Image } \\
\text { Name }\end{array}$ & $\begin{array}{l}\text { Wavel } \\
\text { et } \\
\text { Name }\end{array}$ & $\begin{array}{l}\text { Approx. } \\
\text { coefficie } \\
\text { nts }\end{array}$ & $\begin{array}{l}\text { Horizont } \\
\text { al Detail }\end{array}$ & $\begin{array}{l}\text { Vertical } \\
\text { Detail }\end{array}$ & $\begin{array}{c}\text { Diagonal } \\
\text { Detail }\end{array}$ \\
\hline \multirow[t]{3}{*}{ Lena } & Kekre & 98.8116 & 0.3544 & 0.7850 & 0.0490 \\
\hline & Haar & 98.8116 & 0.3544 & 0.7850 & 0.0490 \\
\hline & $\mathrm{Db} 2$ & 99.0780 & 0.3444 & 0.5418 & 0.0358 \\
\hline \multirow{3}{*}{$\begin{array}{c}\text { Pepper } \\
\text { s }\end{array}$} & Kekre & 99.7323 & 0.1615 & 0.0871 & 0.0191 \\
\hline & Haar & 99.7323 & 0.1615 & 0.0871 & 0.0191 \\
\hline & $\mathrm{Db} 2$ & 99.8625 & 0.0829 & 0.0420 & 0.0126 \\
\hline \multirow[t]{3}{*}{ SFO } & Kekre & 99.5410 & 0.1863 & 0.2269 & 0.0459 \\
\hline & Haar & 99.5410 & 0.1863 & 0.2269 & 0.0459 \\
\hline & $\mathrm{Db} 2$ & 99.6693 & 0.1398 & 0.1577 & 0.0332 \\
\hline \multirow[t]{3}{*}{ Rice } & Kekre & 99.2723 & 0.2711 & 0.3681 & 0.0884 \\
\hline & Haar & 99.2723 & 0.2711 & 0.3681 & 0.0884 \\
\hline & $\mathrm{Db} 2$ & 99.5351 & 0.1516 & 0.2439 & 0.0693 \\
\hline
\end{tabular}

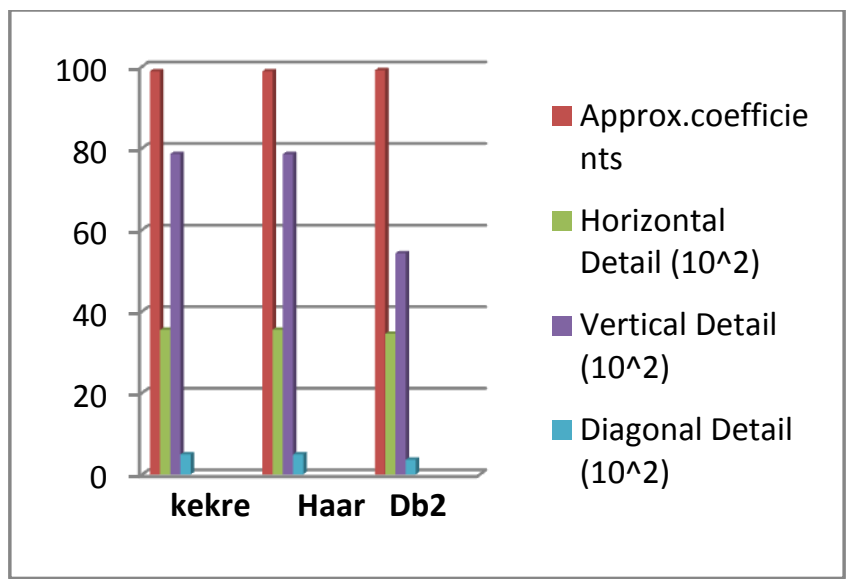

Figure 12: Wavelet vs. Energy for image Leena

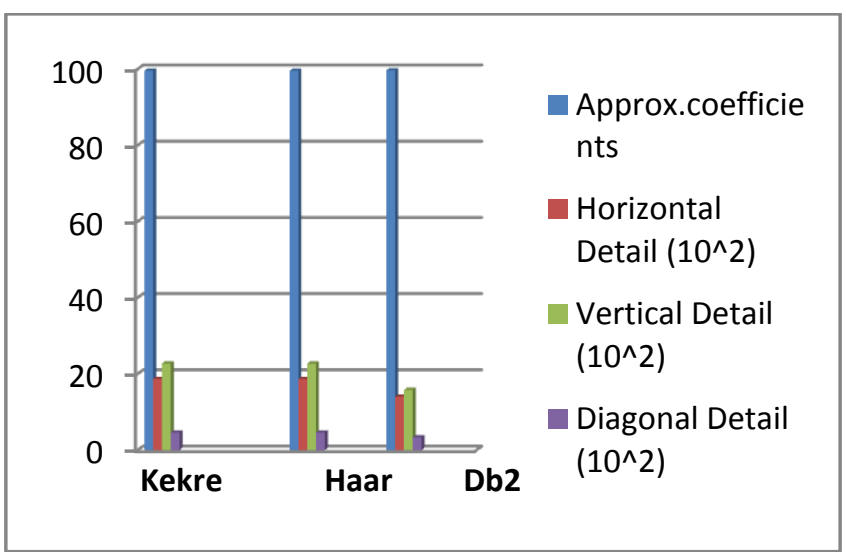

Figure 13: Wavelet vs. Energy for image SFO

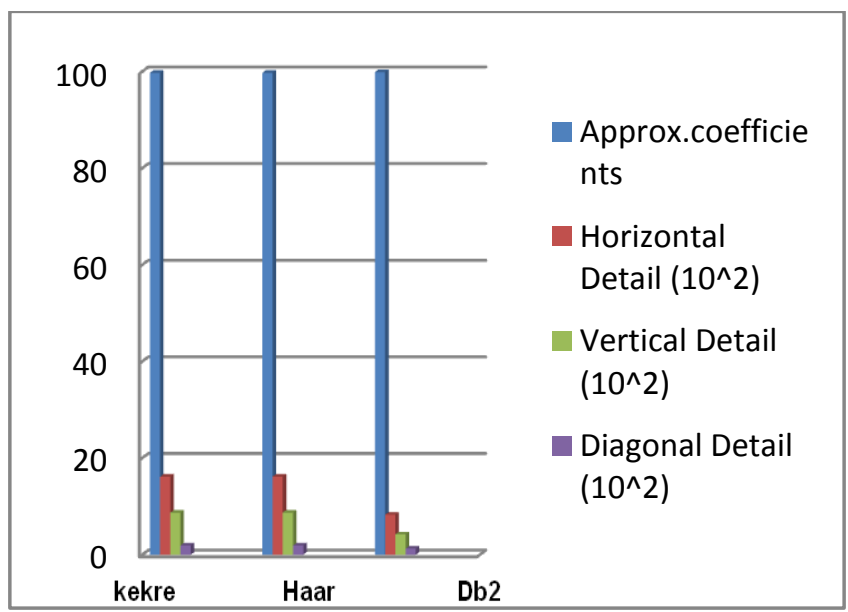

Figure 14: Wavelet vs. Energy for image Peppers 


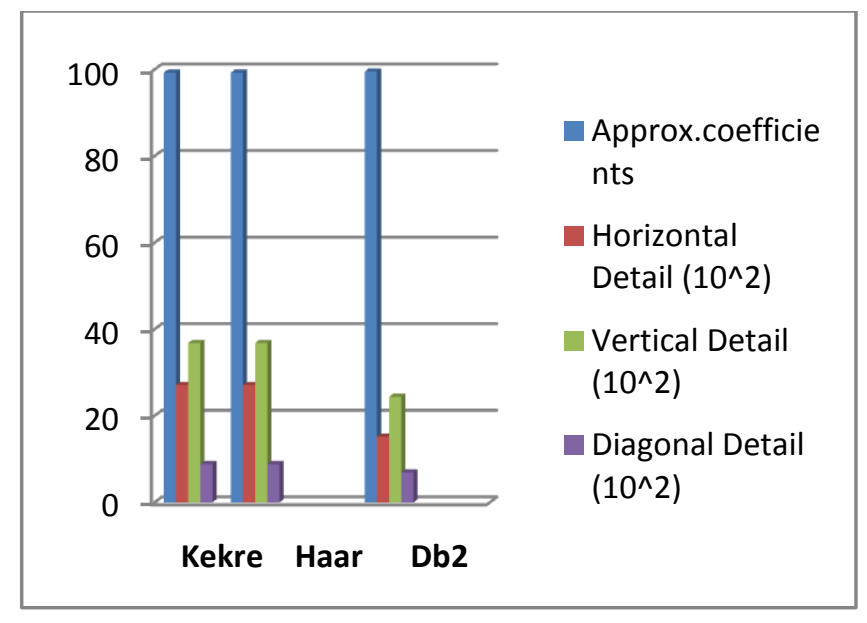

Figure 15: Wavelet vs. Energy for image Rice

From the Table. 1 it is found that maximum energy in all images are in the approximate coefficients, but the amount of energy in the LL band is image dependent. In all images the energy in LL, $\mathrm{LH}, \mathrm{HL}$ and $\mathrm{HH}$ band when kekres transform is used is same as that when Haar transform is used. In case of Daubechies wavelet the energy in the LL band is more compared to Kekres and Haar transform and then energy drastically reduces. The energy in other bands is proportional to the type of edges i.e. Horizontal, Vertical, diagonal present in the respective image.

\section{CONCLUSION}

The performance of Kekre's wavelet transform is the same as Haar transform with respect to energy compaction ability .The advantage of Kekre's wavelet over Haar is that the coefficients of the Kekres matrix are integers and computational burden and quantization problems are less in this transform. Another advantage is that Kekres matrix can be generated for any order unlike Haar where the order hast to be an integer power of two (i.e. $2,4,8,16 \ldots$ )

\section{REFERENCES}

[1] Amara Grap at: http://www.amara.com/IEEEwave/IEEEwavelet.html, accessed on August 9, 2011.

[2] A.W.Galli, G.T.Heydt, P.F.Rebiero, Exploring the power of wavelet analysis,IEEE computer applicationsin power, October 1996.

[3] H. B. Kekre, Archan Athawale,Dipali Sadavarti, Algorithm to Generate Kekre's Wavelet Transform from Kekre's Transform,IJSET, June 2010.

[4] Subband coding of images, John W.Woods, Sean D. Oneil, IEEE transactions on acoustic speech and signal processing, vol - assp 34.

[5] Perfect reconstruction two-channel linear phase quadraturemirror filter (QMF) bank using Kekre's transform matrix, B.Marakarkandy, B.K.Mishra, pp 180-184 , ICWET 2011 